\title{
ACIDEZ NA VINIFICAÇÃO EM TINTO DAS UVAS ISABEL, CABERNET SAUVIGNON E CABERNET FRANC
}

\author{
THE ACIDITY IN THE VINIFICATION OF ISABELLA, \\ CABERNET SAUVIGNON, AND CABERNET FRANC RED GRAPES
}

\author{
Luiz Antenor Rizzon ${ }^{1}$ Alberto Miele ${ }^{2}$
}

\section{RESUMO}

A acidez é uma das características gustativas mais importantes dos vinhos e influencia sua estabilidade e coloração. Devido à insolubilização do ácido tartárico sob a forma de sais, a acidez titulável e o $\mathrm{pH}$ podem ser alterados durante a vinificação de acordo com o teor de potássio da uva. Este trabalho avaliou a evolução da acidez durante a vinificação de três cultivares de uvas tintas (Isabel - Vitis labrusca -, Cabernet Sauvignon e Cabernet Franc - Vitis vinifera) da Serra Gaúcha. Os vinhos foram elaborados por microvinificação na safra de 1995, sendo avaliados a evolução da acidez titulável, pH, ácido tartárico e potássio imediatamente após o esmagamento da uva, na descuba $e$ após a fermentação alcoólica, a fermentação malolática e a estabilização tartárica, totalizando análises em cinco fases da vinificação. Os resultados mostraram uma evolução diferente da acidez, avaliados através do $\mathrm{pH}$, da acidez titulável, do ácido tartárico e do potássio, na vinificação em tinto da uva Isabel em relação à Cabernet Sauvignon e à Cabernet Franc, nas fases compreendidas entre o esmagamento da uva e a descuba. $O$ vinho Isabel se caracterizou por apresentar teores mais elevados de acidez titulável e ácido tartárico e mais baixos de potássio e pH, em relação aos vinhos Cabernet Sauvignon e Cabernet Franc.

Palavras-chave: vinho, composição química, enologia, acidez.

\section{SUMMARY}

The acidity is an important sensory characteristic of the wine, and influences stability and collor. The insolubility of tartaric acid in the vinification by salt forms can change the titratable acidity and the $\mathrm{pH}$ of wines. This work evaluated the acidity evolution during the vinification of Isabella, Cabernet Sauvignon, and Cabernet Franc varieties in the Serra Gaucha region. The wines were elaborated by the microvinification process in the 1995 vintage. The evolution of titratable acidity, $\mathrm{pH}$, tartaric acid, and potassium were analyzed in five phases of winemaking: immediately after crushing, after cap removal, and after alcoholic fermentation, malolactic fermentation and tartrate stabilization. Results showed a different evolution of acidity parameters in the Isabella, as compared to Cabernet Sauvignon and Cabernet Franc varieties. The Isabella wine showed higher levels of titratable acidity and tartaric acid, and lower $\mathrm{pH}$ and potassium than Cabernet Sauvignon and Cabernet Franc wines.

Key words: wine , chemical composition, enology, acidity.

\section{INTRODUÇÃO}

A acidez do mosto e do vinho pode ser avaliada através da acidez real, expressa pelo $\mathrm{pH}$ ,que representa a concentração de hidrogênio iônico do vinho, da acidez titulável e da concentração dos ácidos orgânicos. $\mathrm{O}$ pH do vinho depende do tipo e da concentração dos ácidos orgânicos e da concentração de cátions, especialmente do potássio. Os fatores relacionados à acidez do vinho tem participação importante nas características sensoriais e na estabilidade físico-química e biológica do vinho. A acidez do vinho é diretamente relacionada à composição do mosto especialmente à sua acidez, à concentração de potássio e à predominância do ácido tartárico em relação ao málico (GABAS et al., 1994).

\footnotetext{
${ }^{1}$ Engenheiro Agrônomo, Embrapa Uva e Vinho, CP 130, 95700-000, Bento Gonçalves, RS. E-mail: rizzon@cnpuv.embrapa.br. Autor para correspondência.

${ }^{2}$ Engenheiro Agrônomo, Embrapa Uva e Vinho. Bolsista PQ do CNPq. E-mail: miele @ cnpuv.embrapa.br.

Recebido para publicação em 27.03.01. Aprovado em 08.08.01
} 
Entre os fatores que contribuem para aumentar a acidez titulável do vinho na vinificação em tinto, constata-se o efeito da atividade fermentativa de determinadas leveduras com capacidade para produção de ácidos orgânicos, como o succínico, o pirúvico e o lático (GIACHINI, 1996). Outro provável fator que concorre para aumentar a acidez na vinificação em tinto é a liberação de ácidos orgânicos da película para o mosto por ocasião da maceração.

Entre os fatores que interferem no equilíbrio ácido-base e que modificam o pH estão a dissolução dos minerais e ácidos orgânicos da película e da polpa da uva na maceração; a síntese de ácidos orgânicos na fermentação alcoólica; a degradação do ácido málico na fermentação malolática; e a precipitação do ácido tartárico na forma de bitartarato de potássio e tartarato neutro de cálcio.

Considerando a importância dos vinhos Isabel, Cabernet Sauvignon e Cabernet Franc para a vitivinicultura da Serra Gaúcha e a sua especificidade em relação aos fatores que influenciam a acidez, realizou-se o presente trabalho com o objetivo de comparar a evolução da acidez na vinificação dessas três cultivares de uvas tintas.

\section{MATERIAL E MÉTODOS}

O trabalho foi realizado na Embrapa Uva e Vinho e avaliou a evolução da acidez titulável, pH, ácido tartárico e potássio, nas principais etapas da vinificação em tinto das uvas Isabel (Vitis labrusca), Cabernet Sauvignon e Cabernet Franc, ambas Vitis vinifera.

A colheita da uva foi realizada em 1995 por ocasião de sua maturação industrial e o transporte efetuado em caixas plásticas de $20 \mathrm{~kg}$. Inicialmente, separou-se a ráquis e esmagou-se a uva. O mosto foi colocado em recipientes de vidro de $20 \mathrm{~L}$, adaptados com válvula de Müller e fermentado em uma sala com temperatura controlada de $23^{\circ} \mathrm{C}$ a $25^{\circ} \mathrm{C}$. A seguir, adicionou-se $\mathrm{SO}_{2}(40 \mathrm{mg} / \mathrm{L})$ e levedura seca ativa - Saccharomyces cerevisiae $(150 \mathrm{mg} / \mathrm{L})$. O período de maceração foi de cinco dias, com duas remontagens diárias. Cada microvinificação foi feita em duplicata. Uma vez concluída a fermentação alcoólica, fez-se a primeira trasfega, aproximadamente 30 dias após o esmagamento da uva. Os vinhos permaneceram nesses recipientes até completar a fermentação malolática, aproximadamente 45 dias após o término da fermentação alcoólica, a qual ocorreu espontaneamente. A seguir, os vinhos foram trasfegados novamente, adicionando-se mais uma dose de $\mathrm{SO}_{2}(50 \mathrm{mg} / \mathrm{L})$; estabilizados a $-4^{\circ} \mathrm{C}$ por um período de dez dias; filtrados com pré-filtro de microfibra de vidro, com porosidade de $8 \mu \mathrm{m}$, e engarrafados.

A retirada das amostras para análise foi feita na seguinte seqüência: 1) imediatamente após o esmagamento da uva; 2) na descuba; 3) após a fermentação alcóolica; 4) após a fermentação malolática; e 5) após a estabilização tartárica.

A acidez titulável foi feita titulando $5 \mathrm{~mL}$ de vinho com uma solução alcalina de $\mathrm{NaOH}$, utilizando-se o azul de bromotimol como indicador (USSEGLIO-TOMASSET, 1995). A determinação do $\mathrm{pH}$ foi realizada em um aparelho equipado com eletrodo de vidro calibrado pelo uso das soluções padrões de $\mathrm{pH} 3,0$ e $\mathrm{pH}$ 4,0.

O potássio foi determinado por emissão de chama em espectrofotômetro de absorção atômica, marca Perkin-Elmer, modelo 2380 (PERKIN-ELMER, 1976).

O ácido tartárico foi analisado através da cromatografia líquida de alta eficiência (CLAE) em aparelho Varian 5000 equipado com um injetor Rheodyne de $20 \mu \mathrm{L}$ de volume e uma coluna Varian MCH-NCAP-5 de 4mm x 15cm (AUGUSTE, 1979).

\section{RESULTADOS E DISCUSSÃO}

A evolução da acidez titulável, do $\mathrm{pH}$, do ácido tartárico e do potássio nas principais fases da vinificação em tinto das uvas Isabel, Cabernet Sauvignon e Cabernet Franc, safra de 1995, está representada nas Figuras 1, 2, 3 e 4.

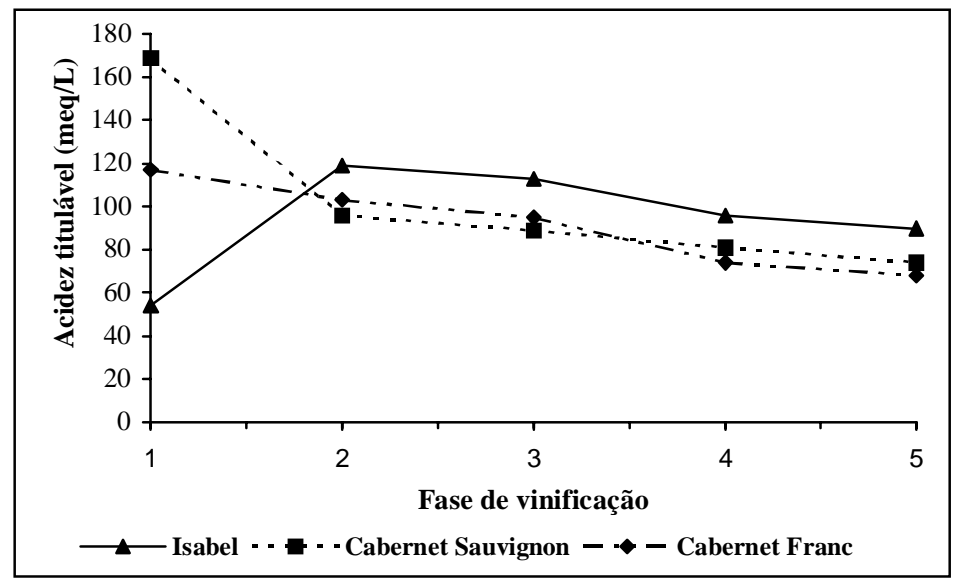

Figura 1 - Evolução da acidez titulável na vinificação em tinto das uvas Isabel, Cabernet Sauvignon e Cabernet Franc, safra 1995, determinada após o esmagamento da uva (1), na descuba (2), após a fermentação alcoólica (3), após a fermentação malolática (4) e após a estabilização tartárica (5). Bento Goncalves, RS, 1995. 
Observou-se um comportamento diferente na evolução da acidez titulável da uva Isabel em relação à Cabernet Sauvignon e Cabernet Franc, resultados semelhantes aos indicados por IDE et $\boldsymbol{a l}$. (1993). O mosto da uva Isabel tem baixo teor de acidez titulável e mostra um aumento importante no período compreendido entre o esmagamento da uva e a descuba. As duas cultivares de Vitis vinifera, ao contrário, caracterizaram-se por apresentarem mosto com acidez titulável elevada e diminuição acentuada de seu teor no mesmo período. Esse comportamento distinto da evolução da acidez titulável entre a cultivar Vitis labrusca e as duas Vitis vinifera foi devido à composição do fruto em relação aos ácidos orgânicos e ao tamanho da baga, que determina proporção diferente

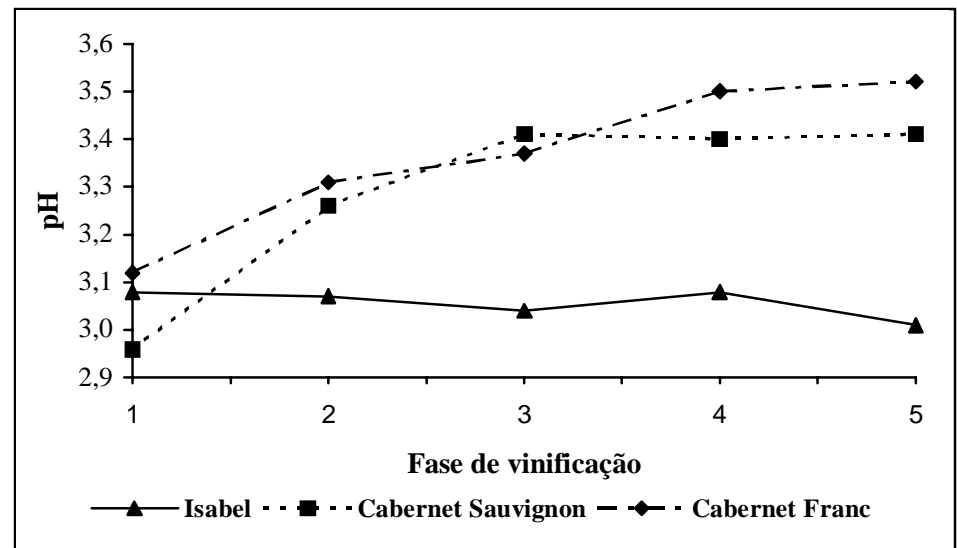

Figura 2 - Evolução do pH na vinificação em tinto das uvas Isabel, Cabernet Sauvignon e Cabernet Franc, safra 1995, determinada após o esmagamento da uva (1), na descuba (2), após a fermentação alcoólica (3), após a fermentação malolática (4) e após a estabilização tartárica (5). Bento Gonçalves, RS, 1995.

$\mathrm{O}$ pH é uma das características mais
tes do vinho tinto, pois além de interferir na entre a película e a polpa. $\mathrm{Na}$ uva Isabel, a película é mais ácida em relação à Cabernet Sauvignon e à Cabernet Franc. Além disso, a uva Isabel se caracteriza por ter bagas, aproximadamente, 1,5 vez maiores, o que determina menor proporção de película em relação à polpa (RIZZON et al., 2000).

Nas demais fases da vinificação constatou-se uma redução da acidez titulável para todas as cultivares, no entanto, não foi tão marcante quanto na maceração. Resultados semelhantes com uvas tintas viníferas foram encontrados por RIZZON et al. (1998) em estudo efetuado com uvas de três regiões vitícolas do Rio Grande do Sul e por MANFROI \& RIZZON (1996), quando estudaram a influência do tempo de maceração nas características fisico-químicas e minerais do vinho Cabernet Sauvignon.

No final da vinificação, constatou-se que o vinho Isabel apresentou teor mais elevado de acidez titulável em comparação com o Cabernet Sauvignon e o Cabernet Franc. Os teores de acidez titulável do vinho Cabernet Sauvignon aqui encontrados foram similares àqueles detectados em trabalho anterior, no qual foram analisados vinhos comerciais (RIZZON \& MIELE, 1997).

Observou-se que a cultivar Isabel tem tendência a diminuir o $\mathrm{pH}$ nas diferentes fases da vinificação, exceto na fermentação malolática onde apresentou um pequeno aumento. Nas cultivares Cabernet Sauvignon e Cabernet Franc, ao contrário, constatou-se um aumento no valor do $\mathrm{pH}$, que foi mais evidente entre o esmagamento da uva e a descuba (Figura 2).

Os fatores que interferem na variação do pH na vinificação estão relacionados com a liberação de ácidos orgânicos e minerais da película para o mosto, especialmente o potássio. cor, exerce um efeito pronunciado sobre o gosto. Vinhos com $\mathrm{pH}$ elevado são mais suscetíveis às alterações oxidativas e biológicas, uma vez que o teor de dióxido de enxofre livre é proporcionalmente menor (AERNY, 1985).

A fase em que ocorreu maior aumento de $\mathrm{pH}$ nas cultivares Cabernet Sauvignon e Cabernet Franc foi entre o esmagamento da uva e a descuba. A liberação de potássio da película para o mosto durante a maceração e a síntese do etanol durante a fermentação alcoólica favorecem a insolubilização e posterior precipitação do bitartarato de potássio, o que determina a elevação do $\mathrm{pH}$ do vinho (BOULTON, 1980; RIZZON 1985). Por outro lado, a dissolução dos ácidos tartárico, málico e cítrico da película para o mosto, bem como a formação de outros ácidos na fermentação alcoólica, agem de maneira contrária, isto é, impedem o aumento mais expressivo do $\mathrm{pH}$.

A elevação do $\mathrm{pH}$ deveu-se à transformação do ácido málico em ácido lático pelas bactérias láticas. A fermentação malolática provocou aumento no pH dos vinhos Isabel e Cabernet Franc, mas uma pequena redução naqueles de Cabernet Sauvignon, provavelmente devido ao aumento da proporção de ácidos livres.

Constatou-se uma variação do teor de ácido tartárico entre as cultivares estudadas, principalmente na fase compreendida entre $\mathrm{o}$ esmagamento da uva e a descuba (Figura 3). Nesse período, o vinho Isabel se caracterizou por apresentar um aumento acentuado do teor de ácido tartárico, enquanto os das cultivares Vitis vinifera, ao contrário, tiveram uma redução de seu teor. Nas 
demais fases, constatou-se uma redução do ácido tartárico para todas as cultivares. A evolução do ácido tartárico é semelhante à verificada anteriormente para a acidez titulável, o que se justifica por ele ser o principal ácido da uva e do vinho. Os resultados obtidos indicam que o vinho Isabel apresentou duas vezes mais ácido tartárico em relação aos vinhos Cabernet Sauvignon e Cabernet Franc, o que está de acordo com o trabalho efetuado sobre a concentração do teor de ácido tartárico dos vinhos da Serra Gaúcha (RIZZON \& MIELE, 2001). Como conseqüência, o $\mathrm{pH}$ foi mais baixo e a acidez titulável mais elevada.

Constatou-se um aumento acentuado de potássio da mesma forma como foi anteriormente observado para o ácido tartárico, liberado pela película para o vinho Isabel entre o esmagamento da uva e a descuba (Figura 4). No entanto, o teor de potássio ficou sempre abaixo daquele detectado nas cultivares de Vitis vinifera. Nas vinificações das cultivares Cabernet Sauvignon e Cabernet Franc, observou-se redução contínua em todas as fases estudadas, devido à precipitação na forma de bitartarato.

Durante a maceração, ocorre a extração de potássio da película e sua liberação para o mosto. Os valores refletem a relação entre o potássio extraído e a taxa de precipitação de potássio na forma salificada de bitartarato de potássio. A redução do teor de potássio evidencia o predomínio dos fatores responsáveis pela precipitação tartárica em relação à extração de potássio da parte sólida da uva. A solubilidade do bitartarato de potássio diminui com a formação de álcool, mas é favorecida pela presença dos ânions malato e lactato (GABAS et al., 1994).

\section{CONCLUSÕES}

Constatou-se uma evolução diferente dos constituintes da acidez - acidez titulável, pH, ácido tartárico e potássio -, na vinificação em tinto da uva Isabel em relação à Cabernet Sauvignon e Cabernet Franc, na fase compreendida entre o esmagamento da uva e a descuba.

Nas demais fases da vinificação estudadas (descuba, após a fermentação alcoólica, após a fermentação malolática e após a estabilização tartárica), observou-se uma evolução semelhante

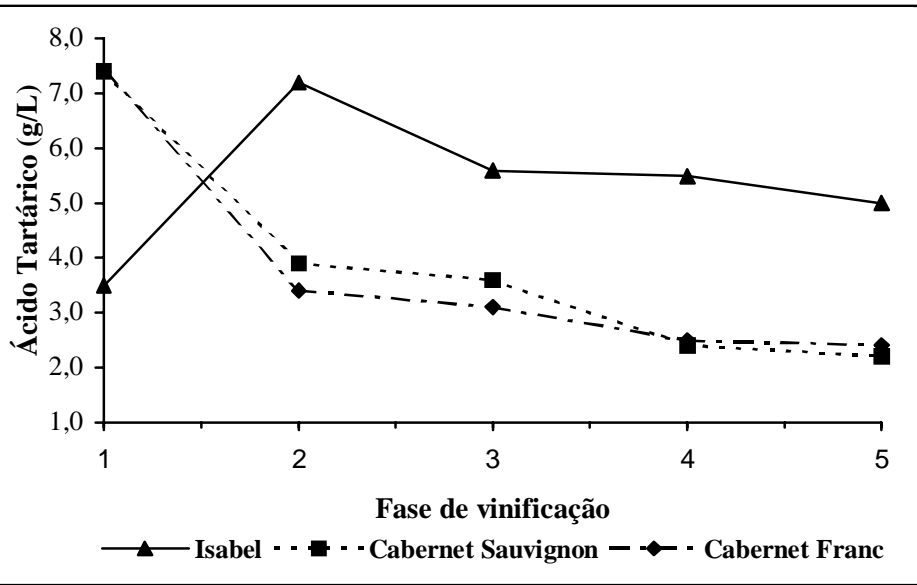

Figura 3 - Evolução do ácido tartárico na vinificação em tinto das uvas Isabel, Cabernet Sauvignon e Cabernet Franc, safra 1995, determinada após o esmagamento da uva (1), na descuba (2), após a fermentação alcoólica (3), após a fermentação malolática (4) e após a estabilização tartárica (5). Bento Gonçalves, RS, 1995

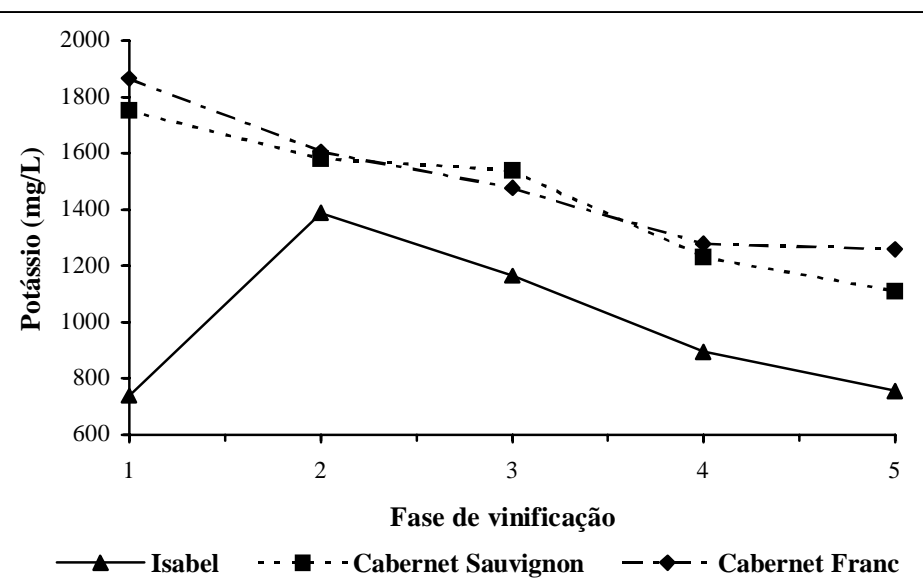

Figura 4 - Evolução do potássio na vinificação em tinto das uvas Isabel, Cabernet Sauvignon e Cabernet Franc, safra 1995, determinada após o esmagamento da uva (1), na descuba (2), após a fermentação alcoólica (3), após a fermentação malolática (4) e após a estabilização tartárica (5). Bento Gonçalves, RS, 1995.

para as variáveis estudadas, nos vinhos Isabel, Cabernet Sauvignon e Cabernet Franc.

Constataram-se teores mais elevados de acidez titulável e de ácido tartárico e mais baixos de potássio e $\mathrm{pH}$ nos vinhos Isabel em relação aos vinhos Cabernet Sauvignon e Cabernet Franc.

\section{REFERÊNCIAS BIBLIOGRÁFICAS}

AERNY, J. Définition de la qualité de la vendange. Revue Suisse de Viticulture, Arboriculture, Horticulture, Nyon, v.17, n.4, p.219-223, 1985.

AUGUSTE, M.H. Application de la chromatographie en phase liquide à haute pression à l'analyse des moûts et des vins. Talence, France, 1979. 135p. Tese (Doctorat en Oenologie - Ampélologie) - Université de Bordeaux II, 1979. 
BOULTON, R. The general relationship between potassium, sodium and $\mathrm{pH}$ in grape juice and wine. American Journal of Enology and Viticulture, Davis, v.31, n.2, p.182-186, 1980 .

GABAS, N., RATSIMBA, B., GERBAUD, V. Les sels tartriques dans les vins: solubilité et sursaturation. In: La microbiologie des vins mousseux: la stabilisation des vins - mécanismes et évaluation. Toulouse : Lallemand, 1994. 95-98p.

GIACHINI, R.A. Avaliação de parâmetros na produção de acidez fixa por leveduras de uso enológico. Caxias do Sul, 1996. 90p. Dissertação (Mestrado em Biotecnologia) Programa de Mestrado em Biotecnologia, Universidade de Caxias. 1996.

IDE, G.M., RIZZON, L.A., DAUDT, C.E. Influência do tempo de maceração do vinho Isabel e Merlot. Boletim da Sociedade Brasileira de Ciência e Tecnologia de Alimentos, Campinas, v.27, n.2, p.88-95, 1993.

MANFROI, V., RIZZON, L.A. Influência do tempo de maceração e do número de recalques nas características físico-químicas e minerais do vinho Cabernet Sauvignon. Boletim da Sociedade Brasileira de Ciência e Tecnologia de Alimentos, Campinas, v.30, n.1, p.60-65, 1996.

PERKIN-ELMER. Analytical methods for atomic absorption spectrophotometry. Norwalk : Perkin-Elmer, 1976. 432p.
RIZZON, L.A. Incidence de la macération sur la composition chimique des vins. Talence, France, 1985. 225p. Tese (Doctorat en Oenologie, Ampélologie) - Université de Bordeaux II, 1985.

RIZZON, L.A., MIELE, A. Caractéristiques analytiques des vins Cabernet Sauvignon produits et commercialisés au Brésil. In: IN VINO ANALYTICA SCIENTIA, 1, 1997, Bordeaux. Livre de résumés... Bordeaux : Fédération Européenne des Sociétés Chimiques/Société Française de Chimie/Office International de la Vigne et du Vin, 1997. p.478-481.

RIZZON, L.A., ZANUZ, M.C., MIELE, A. Evolução da acidez durante a vinificação de uvas tintas de três regiões vitícolas do Rio Grande do Sul. Ciência e Tecnologia de Alimentos, Campinas, v.18, n.2, p.179-183, 1998.

RIZZON, L.A., MIELE, A., MENEGUZZO, J. Avaliação da cv. Isabel para a elaboração de vinho tinto. Ciência e Tecnologia de Alimentos, Campinas, v.20, n.1, p.115-121, 2000.

RIZZON, L.A., MIELE, A. Concentração de ácido tartárico dos vinhos da Serra Gaúcha. Ciência Rural, Santa Maria, v.31. n.5, p.893-895, 2001.

USSEGLIO-TOMASSET, L. Chimica enologica. Brescia: AEB, 1995. 431p. 